\title{
Elevated Concentration of Defensins in Hepatitis C Virus-Infected Patients
}

\author{
Ehab H. Mattar, ${ }^{1}$ Hussein A. Almehdar, ${ }^{1}$ Abdullah A. AlJaddawi, ${ }^{1}$ \\ Isam ElDin M. Abu Zeid, ${ }^{1}$ and Elrashdy M. Redwan ${ }^{1,2}$ \\ ${ }^{1}$ Department of Biological Sciences, Faculty of Sciences, King Abdulaziz University, P.O. Box 80203, Jeddah, Saudi Arabia \\ ${ }^{2}$ Therapeutic and Protective Proteins Laboratory, Protein Research Department, Genetic Engineering and \\ Biotechnology Research Institute, City for Scientific Research and Technology Applications, New Borg EL-Arab, \\ Alexandria 21934, Egypt
}

Correspondence should be addressed to Elrashdy M. Redwan; lradwan@kau.edu.sa

Received 28 January 2016; Revised 17 April 2016; Accepted 27 April 2016

Academic Editor: Ghislain Opdenakker

Copyright (C) 2016 Ehab H. Mattar et al. This is an open access article distributed under the Creative Commons Attribution License, which permits unrestricted use, distribution, and reproduction in any medium, provided the original work is properly cited.

\begin{abstract}
Hepatitis $\mathrm{C}$ virus (HCV) is the major etiological agent of human non-A and non-B hepatitis, affecting around 180 million people worldwide. Defensins, small cysteine-rich cationic peptides, are shown to have potent antibacterial, antiviral, and antifungal properties. Defensins can be found in both normal and microbial infected patients, at variable concentrations. Notably, viral infections are often associated with elevated concentrations of defensins. The current study aimed to estimate the concentrations of total, $\alpha$-, and $\beta$-defensins in serum taken from normal and HCV-infected patients. 12 healthy (noninfected) and $34 \mathrm{HCV}$-infected patients were enrolled. Standardized immunoassay kits were used to obtain serum concentrations of defensins. The obtained results were calibrated against kit standard reagents. Total defensin concentrations in HCV-infected patients were significantly higher (2to 105 -fold) compared to healthy individuals. The concentrations of $\alpha$-defensins were also significantly elevated in the HCV-infected patients (31-1398 ng/50 $\mu \mathrm{L}$ ). However, concentrations of $\beta$-defensins ranged from $44.5 \mathrm{ng} / 50 \mu \mathrm{L}$ to $1056 \mathrm{ng} / 50 \mu \mathrm{L}$. The results did not reveal differences in serum defensin concentration between male and female HCV-infected patients. A-defensin concentration of $\geq 250 \mathrm{ng} / 50 \mu \mathrm{L}$ was found to contain more $\beta$-defensins than total defensins and $\alpha$-defensins. This study concludes, for the first time, that serum defensin levels are elevated in HCV-infected patients.
\end{abstract}

\section{Introduction}

Hepatitis $\mathrm{C}$ virus $(\mathrm{HCV})$ is an enveloped, single positivestranded RNA virus that belongs to the Flaviviridae family. Its genome consists of around 10,000 nucleotides and encodes a single polyprotein of 3010-3033 amino acids. HCV polyprotein is cleaved by both host cell and viral proteases into at least 10 distinct structural and nonstructural protein products. The major structural proteins are a core $(\mathrm{C})$ protein, two envelope proteins, E1 and E2, and a short hydrophobic peptide p7 [1]. $\mathrm{HCV}$ is a major cause of parenterally transmitted non-A and non-B hepatitis worldwide [2], and infection with HCV is one of the leading causes of chronic liver disease worldwide $[3,4]$. The prevalence of HCV infection has increased during recent years; it is estimated that over 180 million people worldwide are infected with $\mathrm{HCV}$, representing $3 \%$ of the world's population, while, in countries like Egypt, the incidence of HCV infection is as high as 15\% [5]. Efforts to achieve a breakthrough in antiviral clinical research for chronic HCV are currently underway in Western countries [6] and Japan [7].

Today, there is no available vaccine against $\mathrm{HCV}$, and the current treatment for HCV infection is limited to nonselective alpha-interferon (IFN) and ribavirin. However, the Food and Drug Administration has recently approved a list of novel anti-HCV compounds [8]. These emerging antivirals should increase treatment options, particularly for difficult-to-treat patients, such as those suffering from advanced liver diseases or other coinfections, who have poor response rates to current regimens. Although the currently clinically approved and cocktail of anti-HCV therapy is believed to cure more 
than $90 \%$ of infected patients, incidence of viral resistance, null responders, and treatment failure (in addition to poor side-effect profiles and large treatment costs) poses a major limitation that must be resolved. As an RNA virus, HCV very easily develops a resistance to antiviral treatments, due to its error-prone replication properties. Most entry inhibitors (a class of antiretroviral agents) target the host cell components required for HCV entry, such as receptors or key enzymes, and have high genetic barriers to resistance due to their conserved nature. Therefore, these inhibitors tend to not only have pan-genotypic activity against viral infection but also have a greater risk of simultaneously causing cellular toxicity [9].

Defensins belong to a diverse group of antimicrobial peptides with pronounced antimicrobial activity [10-17]. These are short, cationic cysteine-rich polypeptides, which are well known for their high and broad antimicrobial properties [16, 17]. Originally isolated from human and rabbit neutrophils (the most abundant type of white blood cells in most mammals, accounting for $40-75 \%$ of white blood cells) [18], defensins have also been found in various other vertebrates [19], invertebrates [20], insects [21], and plants [22, 23]. These polypeptides play important roles in innate immunity against microbial and viral infections, are involved in adaptive immunity, and are also involved in inflammation, wound repair, expression of cytokines and chemokines, production of histamine, and enhancement of antibody responses [2326]. They are also able to induce and augment antitumour immunity when fused with the nonimmunogenic tumour antigens [27]. Defensins are also activated in signal transduction and regulation of the inflammatory effects, participate in wound healing and chemotaxis, control proliferation, and regulate the release of cytokines [28-30]. Defensin concentrations are shown to be elevated following microbial infection [31]. Levels of defensins in HCV-infected patient have not been estimated yet, which was the main aim of current study.

\section{Materials and Methods}

2.1. Samples and Defensin Estimation Kits. HCV-infected patients (34 samples: 19 male and 15 female) and healthy volunteers (12 samples: 6 male and 6 female) participated in this study. The enrolment criteria were based on thorough history taking: patients were considered eligible if (1) no coinfection with HIV or hepatitis B virus (HBV) was present; (2) they suffered from HCV disease and underwent a complete clinical and laboratory evaluation, including tests for liver function; and (3) their serum contained HCV antibodies (confirmed by measuring serum HCV-RNA titre using quantitative realtime polymerase chain reaction (RT-PCR) and TaqMan technology) [32]. Only HCV genotype 4a-infected patients were enrolled in this study. Venous blood samples were collected from all participants. Blood samples were set to clot and sera were separated by centrifugation, collected, aliquoted, and then stored at $-80^{\circ} \mathrm{C}$ prior to use. Finally, all subjects were informed of the aims of the study and oral consent to participation was given. The study protocol was approved by the local ethical committee and conformed to the ethical guidelines of the 1975 Declaration of Helsinki. Total, $\alpha$-, and $\beta$-defensin estimation kits were purchased from MyBioSource (San Diego, California, USA).

2.2. Defensin Concentration Estimation Kits. Human total, $\alpha$-, and $\beta$-defensin concentration estimation kits were used in accordance with the manufacturer's instructions (MyBioSource, San Diego, California, USA) and standard laboratory enzyme-linked immunosorbent assay (ELISA) protocol, as previously described [33-36]. In brief, $50 \mu \mathrm{L}$ infected or noninfected serum samples, as well as the standard reagent, were pipette into microelisa strips (in duplicate) and incubated at $37^{\circ} \mathrm{C}$ for $60 \mathrm{~min}$, followed by a wash with washing solution (3x). $100 \mu \mathrm{L}$ horseradish peroxidase (HRP) reagent was added to each well and incubated for $60 \mathrm{~min}$ at $37^{\circ} \mathrm{C}$, followed by wash with washing solution ( $\left.4 \mathrm{x}\right) .50 \mu \mathrm{L}$ of chromogen $\mathrm{A}$ and $50 \mu \mathrm{L}$ chromogen $\mathrm{B}$ were added to each strip well, then gently mixed, and incubated for $15 \mathrm{~min}$ at $37^{\circ} \mathrm{C}$, away from direct light, following which $50 \mu \mathrm{L}$ stop solution was added to each well. Following an observed colour change from blue to yellow, the optical density (OD) was read at $450 \mathrm{~nm}$ within $15-30 \mathrm{~min}$ after adding the stop solution. The output reading results were calculated, as per manufacturer's instructions (MyBioSource, San Diego, California, USA), as the average of the duplicate readings for each standard and sample by subtracting the average optical density of the blank/control $\left(V_{\mathrm{B} / \mathrm{C}}\right)$.

2.3. Statistical Analysis. Raw OD data was presented as mean \pm SD. The data obtained was analysed using the unpaired $t$-test. $P$ values of $<0.05$ were considered to be statistically significant.

\section{Results}

3.1. Defensin Concentrations in Noninfected Individuals. In total, 46 human sera were used to calculate human defensin concentrations (total, $\alpha$-, and $\beta$-defensins) using a commercial ELISA (Section 2.2). The serum concentrations of total, $\alpha$-, and $\beta$-defensins in noninfected samples ranged from 18.66 to $2.88 \mathrm{ng} / 50 \mu \mathrm{L}$ with a mean concentration $( \pm \mathrm{SD})$ of $11.68 \pm 8.1 \mathrm{ng} / 50 \mu \mathrm{L}$ (Figures 1-4 and Tables 1-4), with no gender-related differences (data not presented). For total defensins, the calculated concentration was $18.66 \pm 3.5 \mathrm{ng} / \mu \mathrm{L}$, corresponding to the kit standard number $1(31.25 \mathrm{ng} / 50 \mu \mathrm{L})$ and showing a clear significant difference from other kit standards ( 62.5 to $1000 \mathrm{ng} / 50 \mu \mathrm{L}$ ). The differences between human $\alpha$-defensin concentrations and the kit standards started from $31.2 \mathrm{ng} / 50 \mu \mathrm{L}$ (Figure 1 and Table 1). Human $\beta$-defensins concentrations were much lower than any kit standards used.

\subsection{Total Human Defensin Concentrations in HCV-Infected} Patients. The serum concentrations of human defensins (total, $\alpha$-, and $\beta$-defensins) in patients infected with $\mathrm{HCV}$ genotype 4 a were significantly higher $(P<0.0001)$ compared to control. 5 out of 34 (14.71\%) of infected patients had the highest concentrations (1589-1979 ng/50 $\mu \mathrm{L}$ ) of total defensins (Figures 1 and 4 and Tables 1 and 4); 3 of the patients were female, without statistical significance. The 


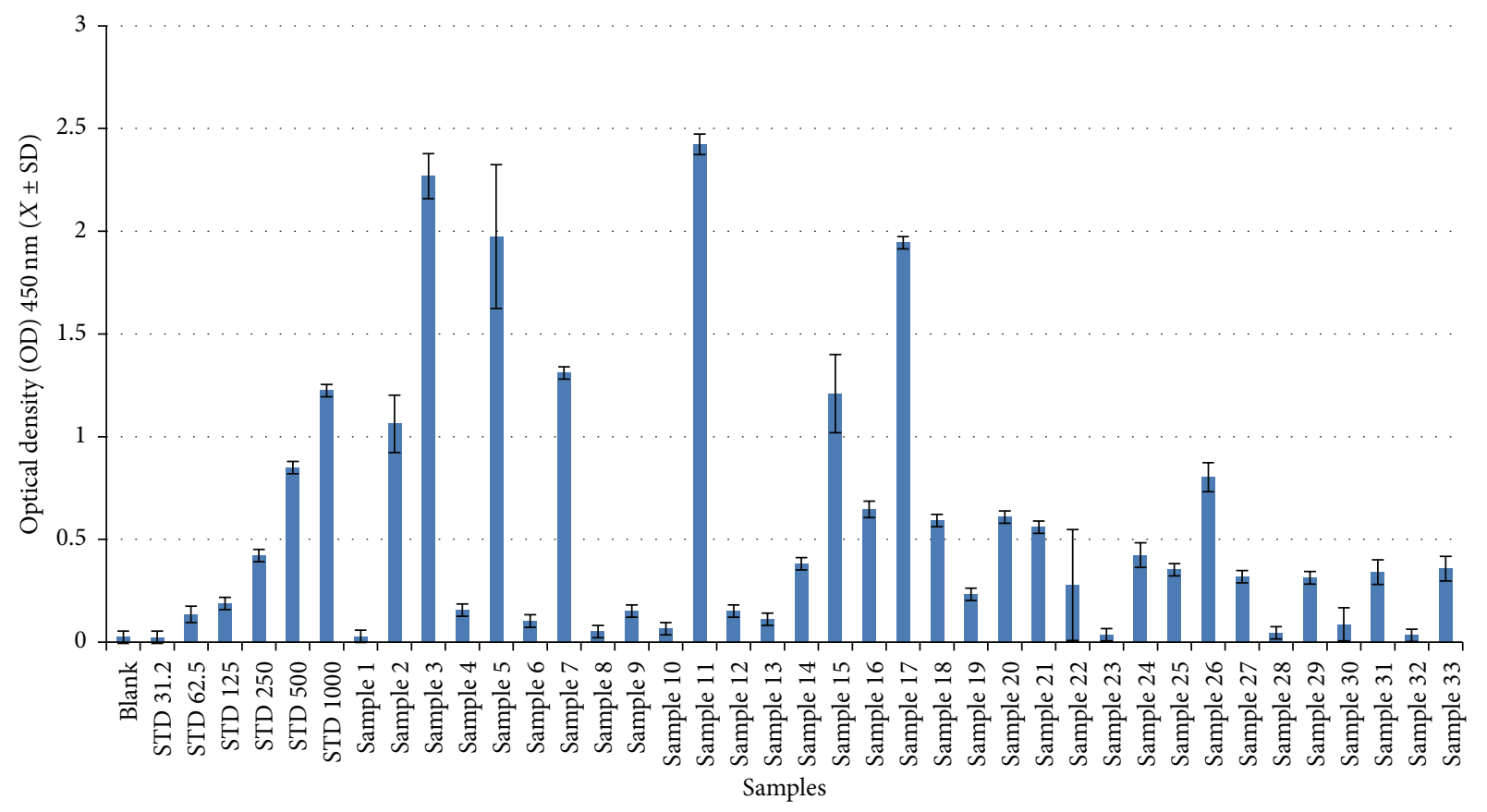

- Total defensins

FIGURE 1: Concentration distribution of human total defensins in patient sera.

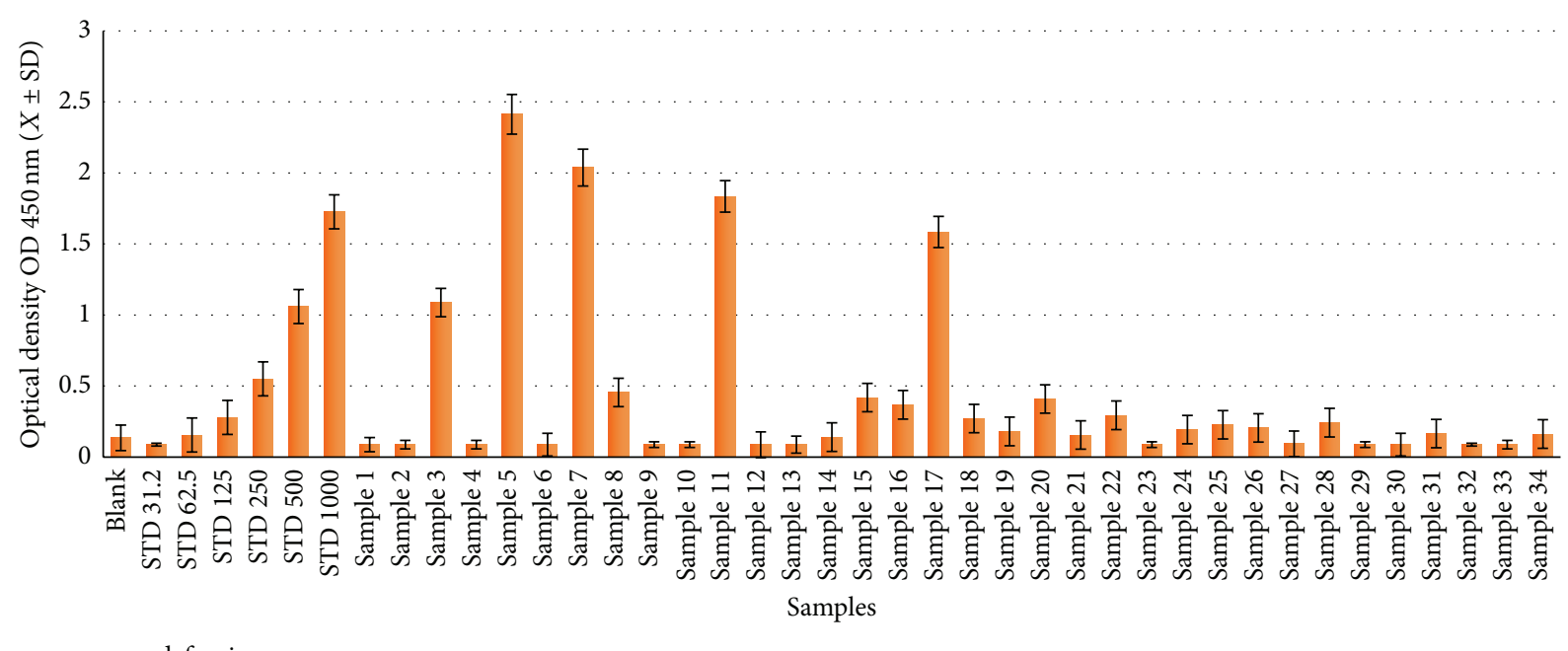

$\alpha$-defensins

FIGURE 2: Concentration distribution of human $\alpha$-defensins in patient sera.

mean concentrations of total defensins in female patients $(449.56 \pm 574.53 \mathrm{ng} / 50 \mu \mathrm{L})$ were not different from those in male patients $(402.18 \pm 562.56 \mathrm{ng} / 50 \mu \mathrm{L}$ ) (Figures 1 and 4 and Tables 1 and 4$)$.

3.3. Human $\alpha$-Defensins Concentrations in HCV-Infected Patients. All HCV-infected patients revealed significantly higher concentrations of human $\alpha$-defensins (31.2-1398 ng/ $50 \mu \mathrm{L})$ in comparison to controls $(13.5 \pm 1.5 \mathrm{ng} / 50 \mu \mathrm{L})$. The majority of HCV-infected patients (70.8\%) showed $\alpha$ defensin concentrations below $250 \mathrm{ng} / 50 \mu \mathrm{L}$, which ranged from $31.2 \mathrm{ng} / 50 \mu \mathrm{L}$ to $206.44 \mathrm{ng} / 50 \mu \mathrm{L}$ (Figures 2 and 4 and
Tables 2 and 4) in their serum. Patients 5, 11, and 17 had the highest $\alpha$-defensin concentrations at 1398.03, 1063.15, and $918.31 \mathrm{ng} / 50 \mu \mathrm{L}$, respectively; two patients (5 and 11) were male and the third patient (17) was female. The concentration of $\alpha$-defensins in both male $(218.26 \pm 378.55 \mathrm{ng} / 50 \mu \mathrm{L})$ and female $(234.29 \pm 356.46 \mathrm{ng} / 50 \mu \mathrm{L})$ patients was nearly equal (Figures 2 and 4 and Tables 2 and 4).

3.4. Human $\beta$-Defensins Concentrations in HCV-Infected Patients. Concentrations of $\beta$-defensins were significantly higher in HCV-infected patient sera $(44.50-1056.11 \mathrm{ng} / 50 \mu \mathrm{L})$ compared to controls $(2.88 \pm 0.14 \mathrm{ng} / 50 \mu \mathrm{L})$. Approximately 


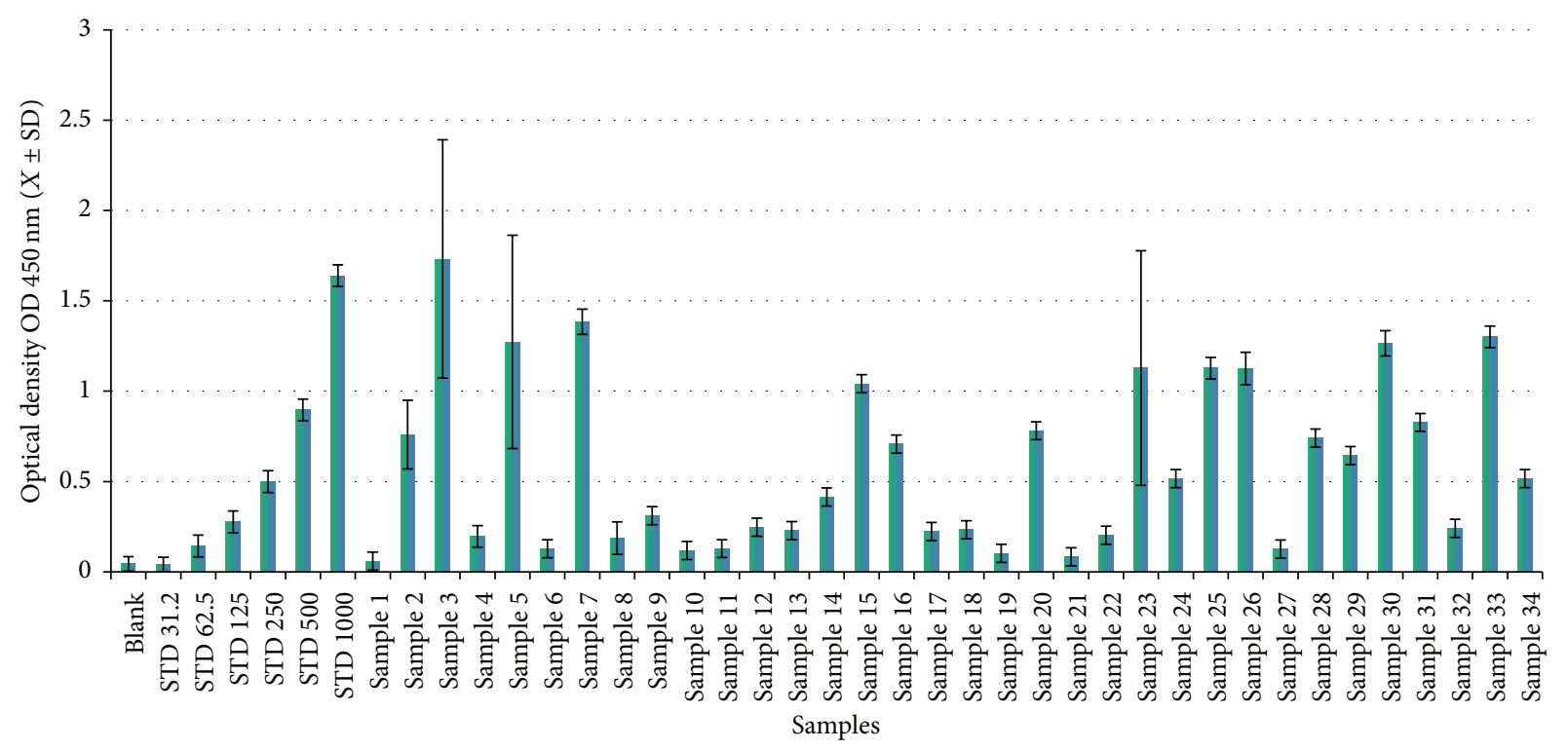

- $\beta$-defensins

FIGURE 3: Concentration distribution of human $\beta$-defensins in patient sera.

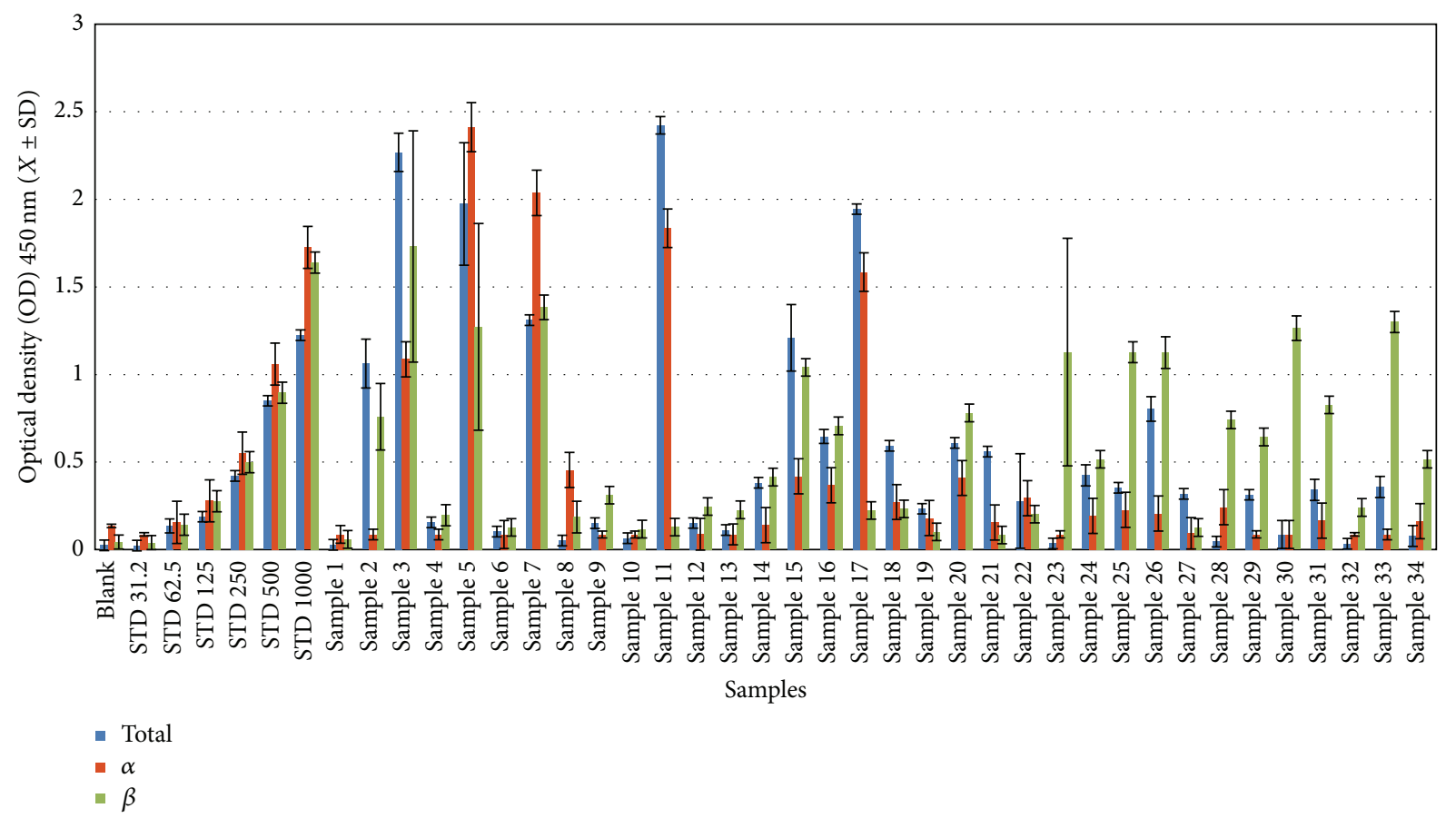

FIGURE 4: Comparison of concentration distribution of human (total, $\alpha$, and $\beta$ ) defensins in patient sera.

$50 \%$ of the patients showed $\beta$-defensin concentrations of $>250 \mathrm{ng} / 50 \mu \mathrm{L}$, ranging from 258 to $1056 \mathrm{ng} / 50 \mu \mathrm{L}$ (Figures 3 and 4 and Tables 3 and 4). The concentrations of $\beta$ defensins in both male $(302.01 \pm 280.69 \mathrm{ng} / 50 \mu \mathrm{L})$ and female $(370.7 \pm 323.8 \mathrm{ng} / 50 \mu \mathrm{L})$ patients were similar (Figures 3 and 4 and Tables 3 and 4). Concentrations of $\beta$-defensins of $500 \mathrm{ng} / 50 \mu \mathrm{L}$ were more commonly found in males (5 patients) than females (3 patients; Table 4). Patients 3, 7, 33, 5 , and 30 were found to have highest $\beta$-defensin concentrations at 1056.11, 843.97, 793.23, 776.15, and $770.97 \mathrm{ng} / 50 \mu \mathrm{L}$, respectively; three of these five patients were female (Figures 3 and 4 and Tables 3 and 4). 
TABLE 1: Total human defensin concentration in HCV patients serum.

\begin{tabular}{|c|c|c|c|c|c|c|}
\hline \multirow{2}{*}{ Variables } & \multicolumn{6}{|c|}{ ANOVA one-way } \\
\hline & Gender & Mean & SD & $N$ & Concentration $(\mathrm{ng} / 50 \mu \mathrm{L})$ & $P$ value \\
\hline Blank & & 0.0145 & 0.03 & 4 & 000 & 00 \\
\hline Health sample & $6 \mathrm{M}, 6 \mathrm{~F}$ & & & 12 & $18.66 \pm 3.5$ & 00 \\
\hline STD 31.2 & Standard & 0.0235 & 0.03 & 2 & 31.2 & 00 \\
\hline STD 62.5 & Standard & 0.1360 & 0.04 & 2 & 62.5 & 00 \\
\hline STD 125 & Standard & 0.1885 & 0.03 & 2 & 125 & 00 \\
\hline STD 250 & Standard & 0.4210 & 0.03 & 2 & 250 & 00 \\
\hline STD 500 & Standard & 0.8500 & 0.03 & 2 & 500 & 00 \\
\hline STD 1000 & Standard & 1.2245 & 0.03 & 2 & 1000 & 00 \\
\hline Sample 1 & M & 0.0282 & 0.03 & 4 & 37.44 & $<0.05$ \\
\hline Sample 2 & M & 1.0625 & 0.14 & 4 & 867.701 & $<0.005$ \\
\hline Sample 3 & $\mathrm{~F}$ & 2.2685 & 0.11 & 4 & 1852.60 & $<0.0001$ \\
\hline Sample 4 & F & 0.1562 & 0.03 & 4 & 103.58 & $<0.05$ \\
\hline Sample 5 & M & 1.9735 & 0.35 & 4 & 1611.68 & $<0.001$ \\
\hline Sample 6 & M & 0.1032 & 0.03 & 4 & 47.43 & $<0.05$ \\
\hline Sample 7 & $\mathrm{~F}$ & 1.3110 & 0.03 & 4 & 1070.64 & $<0.0001$ \\
\hline Sample 8 & M & 0.0520 & 0.03 & 4 & 69.04 & $<0.05$ \\
\hline Sample 9 & M & 0.1512 & 0.03 & 4 & 100.30 & $<0.05$ \\
\hline Sample 10 & $\mathrm{~F}$ & 0.0655 & 0.03 & 4 & 86.96 & $<0.05$ \\
\hline Sample 11 & M & 2.4235 & 0.05 & 4 & 1979.180 & $<0.00001$ \\
\hline Sample 12 & M & 0.1522 & 0.03 & 4 & 100.93 & $<0.05$ \\
\hline Sample 13 & F & 0.1117 & 0.03 & 4 & 51.33 & $<0.05$ \\
\hline Sample 14 & M & 0.3817 & 0.03 & 4 & 226.66 & $<0.005$ \\
\hline Sample 15 & M & 1.2097 & 0.19 & 4 & 987.91 & $<0.001$ \\
\hline Sample 16 & F & 0.6460 & 0.04 & 4 & 380 & $<0.005$ \\
\hline Sample 17 & F & 1.9445 & 0.03 & 4 & 1587.99 & $<0.0001$ \\
\hline Sample 18 & F & 0.5927 & 0.03 & 4 & 242.02 & $<0.05$ \\
\hline Sample 19 & M & 0.2335 & 0.03 & 4 & 138.7 & $<0.05$ \\
\hline Sample 20 & $\mathrm{~F}$ & 0.6095 & 0.03 & 4 & 358.5 & $<0.005$ \\
\hline Sample 21 & M & 0.5602 & 0.03 & 4 & 329.53 & $<0.005$ \\
\hline Sample 22 & M & 0.2785 & 0.27 & 4 & 165.4 & $<0.05$ \\
\hline Sample 23 & M & 0.0360 & 0.03 & 4 & 39.50 & $<0.05$ \\
\hline Sample 24 & $\mathrm{~F}$ & 0.4240 & 0.06 & 4 & 251.78 & $<0.005$ \\
\hline Sample 25 & F & 0.3532 & 0.03 & 4 & 209.74 & $<0.005$ \\
\hline Sample 26 & M & 0.8032 & 0.07 & 4 & 472.5 & $<0.005$ \\
\hline Sample 27 & M & 0.3187 & 0.03 & 4 & 189.25 & $<0.05$ \\
\hline Sample 28 & M & 0.0455 & 0.03 & 4 & 60.41 & $<0.05$ \\
\hline Sample 29 & F & 0.3135 & 0.03 & 4 & 186.16 & $<0.05$ \\
\hline Sample 30 & M & 0.0870 & 0.08 & 4 & 115.51 & $<0.05$ \\
\hline Sample 31 & M & 0.3410 & 0.06 & 4 & 202.5 & $<0.05$ \\
\hline Sample 32 & $\mathrm{~F}$ & 0.0340 & 0.03 & 4 & 45.15 & $<0.05$ \\
\hline Sample 33 & F & 0.3582 & 0.06 & 4 & 212.71 & $<0.05$ \\
\hline Sample 34 & $\mathrm{~F}$ & 0.0785 & 0.06 & 4 & 104.22 & $<0.05$ \\
\hline
\end{tabular}

\section{Discussion}

Defensins are "magic" 28-42 amino acid cationic peptides, assumed to possess a conserved structural fold containing six highly conserved cysteine residues, which form three pairs of highly conserved intramolecular disulfide bonds $[17,37-40]$. Vertebrate defensins are classified as $\alpha-, \beta-$, and $\gamma$-defensins, based on their cellular origin, the spacing between the cysteine residues, and the number and pattern (topology) of their disulfide bridges [17, 38, 40]. In mammals, barrier epithelial cells mostly generate $\beta$-defensins, whereas $\alpha$-defensins are mainly stored in the azurophil granules of neutrophils [16]. In the mouse, Paneth cells and fibroblasts produce at least $17 \alpha$-defensins, whereas various epithelial 
TABLE 2: Human $\alpha$-defensin concentration in HCV patients serum.

\begin{tabular}{|c|c|c|c|c|c|c|}
\hline \multirow{2}{*}{ Variables } & \multicolumn{6}{|c|}{ ANOVA one-way } \\
\hline & Gender & Mean & SD & $N$ & Concentration $(\mathrm{ng} / 50 \mu \mathrm{L})$ & $P$ value \\
\hline Blank & 0.099 & & 0.09 & 4 & 00.00 & 00 \\
\hline Health sample & $6 \mathrm{M}, 6 \mathrm{~F}$ & & & 12 & $13.5 \pm 1.2$ & 00 \\
\hline STD 31.2 & Standard & 0.0870 & 0.01 & 2 & 31.2 & 00 \\
\hline STD 62.5 & Standard & 0.1560 & 0.12 & 2 & 62.5 & 00 \\
\hline STD 125 & Standard & 0.2790 & 0.12 & 2 & 125 & 00 \\
\hline STD 250 & Standard & 0.5510 & 0.12 & 2 & 250 & 00 \\
\hline STD 500 & Standard & 1.0600 & 0.12 & 2 & 500 & 00 \\
\hline STD 1000 & Standard & 1.7260 & 0.12 & 2 & 1000 & 00 \\
\hline Sample 1 & M & 0.0872 & 0.05 & 4 & 31.3 & $<0.05$ \\
\hline Sample 2 & M & 0.0870 & 0.03 & 4 & 31.2 & $<0.005$ \\
\hline Sample 3 & $\mathrm{~F}$ & 1.0872 & 0.10 & 4 & 512.83 & $<0.005$ \\
\hline Sample 4 & $\mathrm{~F}$ & 0.0872 & 0.03 & 4 & 31.3 & $<0.05$ \\
\hline Sample 5 & M & 2.4130 & 0.14 & 4 & 1398.03 & $<0.0001$ \\
\hline Sample 6 & M & 0.0870 & 0.08 & 4 & 31.2 & $<0.05$ \\
\hline Sample 7 & $\mathrm{~F}$ & 2.0375 & 0.13 & 4 & 1180.5 & $<0.0001$ \\
\hline Sample 8 & M & 0.4550 & 0.10 & 4 & 206.44 & $<0.05$ \\
\hline Sample 9 & M & 0.0870 & 0.02 & 4 & 31.2 & $<0.05$ \\
\hline Sample 10 & $\mathrm{~F}$ & 0.0870 & 0.02 & 4 & 31.2 & $<0.05$ \\
\hline Sample 11 & M & 1.8350 & 0.11 & 4 & 1063.15 & $<0.00001$ \\
\hline Sample 12 & M & 0.0880 & 0.09 & 4 & 31.6 & $<0.05$ \\
\hline Sample 13 & F & 0.0872 & 0.06 & 4 & 31.3 & $<0.05$ \\
\hline Sample 14 & M & 0.1405 & 0.10 & 4 & 56.3 & $<0.05$ \\
\hline Sample 15 & M & 0.4190 & 0.10 & 4 & 190.11 & $<0.05$ \\
\hline Sample 16 & F & 0.3680 & 0.10 & 4 & 164.9 & $<0.05$ \\
\hline Sample 17 & F & 1.5850 & 0.11 & 4 & 918.31 & $<0.001$ \\
\hline Sample 18 & F & 0.2720 & 0.10 & 4 & 121.9 & $<0.05$ \\
\hline Sample 19 & M & 0.1805 & 0.10 & 4 & 72.32 & $<0.05$ \\
\hline Sample 20 & $\mathrm{~F}$ & 0.4090 & 0.10 & 4 & 184.21 & $<0.05$ \\
\hline Sample 21 & M & 0.1555 & 0.10 & 4 & 62.3 & $<0.05$ \\
\hline Sample 22 & M & 0.2942 & 0.10 & 4 & 131.81 & $<0.05$ \\
\hline Sample 23 & M & 0.0872 & 0.02 & 4 & 31.3 & $<0.05$ \\
\hline Sample 24 & $\mathrm{~F}$ & 0.1930 & 0.10 & 4 & 77.32 & $<0.005$ \\
\hline Sample 25 & $\mathrm{~F}$ & 0.2272 & 0.10 & 4 & 101.8 & $<0.005$ \\
\hline Sample 26 & M & 0.2062 & 0.10 & 4 & 92.4 & $<0.005$ \\
\hline Sample 27 & M & 0.0937 & 0.09 & 4 & 33.60 & $<0.05$ \\
\hline Sample 28 & M & 0.2422 & 0.10 & 4 & 108.51 & $<0.05$ \\
\hline Sample 29 & $\mathrm{~F}$ & 0.0872 & 0.02 & 4 & 31.3 & $<0.05$ \\
\hline Sample 30 & M & 0.0872 & 0.08 & 4 & 31.3 & $<0.05$ \\
\hline Sample 31 & M & 0.1655 & 0.10 & 4 & 66.31 & $<0.05$ \\
\hline Sample 32 & $\mathrm{~F}$ & 0.0870 & 0.01 & 4 & 31.2 & $<0.05$ \\
\hline Sample 33 & $\mathrm{~F}$ & 0.0872 & 0.03 & 4 & 31.3 & $<0.05$ \\
\hline Sample 34 & $\mathrm{~F}$ & 0.1625 & 0.10 & 4 & 65.10 & $<0.05$ \\
\hline
\end{tabular}

cells and keratinocytes generate $4 \beta$-defensins. The $\alpha$ - and $\beta$-defensins are present in different vertebrate species, where they are found in the granules of immune cells, epithelial tissue, body fluids, and mucosal surfaces [40].

In the current study, circulating concentrations of defensins in $\mathrm{HCV}$ patients were evaluated, for first time worldwide, to determine whether levels of defensins altered during HCV infection. Sera from 12 noninfected and 34 $\mathrm{HCV}$-infected patients were harnessed in order to test this, using the commercial ELISA kits. The obtained results demonstrated that $\mathrm{HCV}$-infected patients had significantly increased $(P<0.005-0.0001)$ levels of defensin (total, $\alpha$-, and $\beta$-defensins) concentrations compared to the noninfected group. The majority of patients (70.8\%) revealed $\alpha$-defensin 
TABLE 3: Human $\beta$-defensin concentration in HCV patients serum.

\begin{tabular}{|c|c|c|c|c|c|c|}
\hline \multirow{2}{*}{ Variables } & \multicolumn{6}{|c|}{ ANOVA one-way } \\
\hline & Gender & Mean & $\mathrm{SD}$ & $N$ & Concentration $(\mathrm{ng} / 50 \mu \mathrm{L})$ & $P$ value \\
\hline Blank & & 0.075 & 0.04 & 4 & 00.00 & 00 \\
\hline Health sample & $6 \mathrm{M}, 6 \mathrm{~F}$ & & & 12 & $2.88 \pm 0.14$ & 00 \\
\hline STD 31.2 & Standard & 0.0405 & 0.04 & 2 & 31.2 & 00 \\
\hline STD 62.5 & Standard & 0.1425 & 0.06 & 2 & 62.5 & 00 \\
\hline STD 125 & Standard & 0.2765 & 0.06 & 2 & 125 & 00 \\
\hline STD 250 & Standard & 0.4995 & 0.06 & 2 & 250 & 00 \\
\hline STD 500 & Standard & 0.8965 & 0.06 & 2 & 500 & 00 \\
\hline STD 1000 & Standard & 1.6395 & 0.06 & 2 & 1000 & 00 \\
\hline Sample 1 & M & 0.0590 & 0.05 & 4 & 45.45 & $<0.05$ \\
\hline Sample 2 & M & 0.7590 & 0.19 & 4 & 379.9 & $<0.005$ \\
\hline Sample 3 & $\mathrm{~F}$ & 1.7315 & 0.66 & 4 & 1056.11 & $<0.0001$ \\
\hline Sample 4 & $\mathrm{~F}$ & 0.1965 & 0.06 & 4 & 86.2 & $<0.05$ \\
\hline Sample 5 & M & 1.2725 & 0.59 & 4 & 776.15 & $<0.001$ \\
\hline Sample 6 & $\mathrm{M}$ & 0.1270 & 0.05 & 4 & 55.70 & $<0.05$ \\
\hline Sample 7 & $\mathrm{~F}$ & 1.3837 & 0.07 & 4 & 843.97 & $<0.001$ \\
\hline Sample 8 & $\mathrm{M}$ & 0.1860 & 0.09 & 4 & 81.6 & $<0.05$ \\
\hline Sample 9 & $\mathrm{M}$ & 0.3110 & 0.05 & 4 & 155.7 & $<0.05$ \\
\hline Sample 10 & $\mathrm{~F}$ & 0.1175 & 0.05 & 4 & 51.53 & $<0.05$ \\
\hline Sample 11 & $\mathrm{M}$ & 0.1285 & 0.05 & 4 & 56.35 & $<0.05$ \\
\hline Sample 12 & $\mathrm{M}$ & 0.2465 & 0.05 & 4 & 111.44 & $<0.05$ \\
\hline Sample 13 & $\mathrm{~F}$ & 0.2275 & 0.05 & 4 & 102.8 & $<0.05$ \\
\hline Sample 14 & $\mathrm{M}$ & 0.4145 & 0.05 & 4 & 207.5 & $<0.05$ \\
\hline Sample 15 & M & 1.0410 & 0.05 & 4 & 634.95 & $<0.001$ \\
\hline Sample 16 & $\mathrm{~F}$ & 0.7070 & 0.05 & 4 & 394.31 & $<0.005$ \\
\hline Sample 17 & $\mathrm{~F}$ & 0.2235 & 0.05 & 4 & 101.1 & $<0.0001$ \\
\hline Sample 18 & $\mathrm{~F}$ & 0.2330 & 0.05 & 4 & 105.33 & $<0.05$ \\
\hline Sample 19 & $\mathrm{M}$ & 0.1015 & 0.05 & 4 & 44.51 & $<0.05$ \\
\hline Sample 20 & $\mathrm{~F}$ & 0.7810 & 0.05 & 4 & 390.9 & $<0.005$ \\
\hline Sample 21 & $\mathrm{M}$ & 0.0835 & 0.05 & 4 & 64.33 & $<0.005$ \\
\hline Sample 22 & M & 0.2030 & 0.05 & 4 & 91.77 & $<0.05$ \\
\hline Sample 23 & $\mathrm{M}$ & 1.1280 & 0.65 & 4 & 688.01 & $<0.005$ \\
\hline Sample 24 & $\mathrm{~F}$ & 0.5165 & 0.05 & 4 & 258.0 & $<0.005$ \\
\hline Sample 25 & $\mathrm{~F}$ & 1.1275 & 0.06 & 4 & 687.71 & $<0.005$ \\
\hline Sample 26 & $\mathrm{M}$ & 1.1250 & 0.09 & 4 & 686.2 & $<0.005$ \\
\hline Sample 27 & $\mathrm{M}$ & 0.1265 & 0.05 & 4 & 55.5 & $<0.05$ \\
\hline Sample 28 & $\mathrm{M}$ & 0.7410 & 0.05 & 4 & 370.9 & $<0.005$ \\
\hline Sample 29 & $\mathrm{~F}$ & 0.6435 & 0.05 & 4 & 322.1 & $<0.005$ \\
\hline Sample 30 & M & 1.2640 & 0.07 & 4 & 770.97 & $<0.001$ \\
\hline Sample 31 & M & 0.8270 & 0.05 & 4 & 461.3 & $<0.005$ \\
\hline Sample 32 & $\mathrm{~F}$ & 0.2410 & 0.05 & 4 & 108.95 & $<0.05$ \\
\hline Sample 33 & $\mathrm{~F}$ & 1.3005 & 0.06 & 4 & 793.23 & $<0.001$ \\
\hline Sample 34 & $\mathrm{~F}$ & 0.5160 & 0.05 & 4 & 258.26 & $<0.005$ \\
\hline
\end{tabular}

concentrations below $250 \mathrm{ng} / 50 \mu \mathrm{L}$. The concentrations of $\alpha$-defensins in both male $(218.26 \pm 378.55 \mathrm{ng} / 50 \mu \mathrm{L})$ and female $(234.29 \pm 356.46 \mathrm{ng} / 50 \mu \mathrm{L})$ patients were virtually equal. The highest $\alpha$-defensin concentrations were reported in patients 5, 11, and $17(1398.03,1063.15$, and $918.31 \mathrm{ng} / 50 \mu \mathrm{L}$, resp.); two patients (5 and 11) were male and the third patient (17) was female. Approximately half the $\mathrm{HCV}$-infected patients showed $\beta$-defensin concentrations of $>250 \mathrm{ng} / 50 \mu \mathrm{L}$. Concentrations of $\beta$-defensins of $500 \mathrm{ng} / 50 \mu \mathrm{L}$ were more commonly found in males ( 5 patients) than in females ( 3 patients). Three of the five HCV-infected patients showing the highest $\beta$-defensin concentrations were female, although gender did not seem to have a significant effect. The high defensins concentrations within these patients may be due 
TABLE 4: Comparison between total, $\alpha$-, and $\beta$-defensin concentration level in HCV patients serum.

\begin{tabular}{|c|c|c|c|c|c|}
\hline \multirow{2}{*}{ Variables } & \multicolumn{5}{|c|}{ Concentration $(\mathrm{ng} / 50 \mu \mathrm{L})$} \\
\hline & Gender & $N$ & Total defensin & $\alpha$-defensin & $\beta$-defensin \\
\hline Health sample & $6 \mathrm{M}, 6 \mathrm{~F}$ & 12 & $18.66 \pm 3.5$ & $13.5 \pm 1.2$ & $2.88 \pm 0.14$ \\
\hline STD 31.2 & Standard & 2 & 31.2 & 31.2 & 31.2 \\
\hline STD 62.5 & Standard & 2 & 62.5 & 62.5 & 62.5 \\
\hline STD 125 & Standard & 2 & 125 & 125 & 125 \\
\hline STD 250 & Standard & 2 & 250 & 250 & 250 \\
\hline STD 500 & Standard & 2 & 500 & 500 & 500 \\
\hline STD 1000 & Standard & 2 & 1000 & 1000 & 1000 \\
\hline Sample 1 & M & 4 & 37.44 & 31.3 & 45.45 \\
\hline Sample 2 & M & 4 & 867.701 & 31.2 & 379.9 \\
\hline Sample 3 & $\mathrm{~F}$ & 4 & 1852.60 & 512.83 & 1056.11 \\
\hline Sample 4 & $\mathrm{~F}$ & 4 & 103.58 & 31.3 & 86.2 \\
\hline Sample 5 & $\mathrm{M}$ & 4 & 1611.68 & 1398.03 & 776.15 \\
\hline Sample 6 & M & 4 & 47.43 & 31.2 & 55.70 \\
\hline Sample 7 & $\mathrm{~F}$ & 4 & 1070.64 & 1180.5 & 843.97 \\
\hline Sample 8 & M & 4 & 69.04 & 206.44 & 81.6 \\
\hline Sample 9 & M & 4 & 100.30 & 31.2 & 155.7 \\
\hline Sample 10 & $\mathrm{~F}$ & 4 & 86.96 & 31.2 & 51.53 \\
\hline Sample 11 & M & 4 & 1979.180 & 1063.15 & 56.35 \\
\hline Sample 12 & $\mathrm{M}$ & 4 & 100.93 & 31.6 & 111.44 \\
\hline Sample 13 & $\mathrm{~F}$ & 4 & 51.33 & 31.3 & 102.8 \\
\hline Sample 14 & $\mathrm{M}$ & 4 & 226.66 & 56.3 & 207.5 \\
\hline Sample 15 & $\mathrm{M}$ & 4 & 987.91 & 190.11 & 634.95 \\
\hline Sample 16 & $\mathrm{~F}$ & 4 & 380 & 164.9 & 394.31 \\
\hline Sample 17 & $\mathrm{~F}$ & 4 & 1587.99 & 918.31 & 101.1 \\
\hline Sample 18 & $\mathrm{~F}$ & 4 & 242.02 & 121.9 & 105.33 \\
\hline Sample 19 & $\mathrm{M}$ & 4 & 138.7 & 72.32 & 44.51 \\
\hline Sample 20 & $\mathrm{~F}$ & 4 & 358.5 & 184.21 & 390.9 \\
\hline Sample 21 & $\mathrm{M}$ & 4 & 329.53 & 62.3 & 64.33 \\
\hline Sample 22 & $\mathrm{M}$ & 4 & 165.4 & 131.81 & 91.77 \\
\hline Sample 23 & M & 4 & 39.50 & 31.3 & 688.01 \\
\hline Sample 24 & $\mathrm{~F}$ & 4 & 251.78 & 77.32 & 258.0 \\
\hline Sample 25 & $\mathrm{~F}$ & 4 & 209.74 & 101.8 & 687.71 \\
\hline Sample 26 & M & 4 & 472.5 & 92.4 & 686.2 \\
\hline Sample 27 & $\mathrm{M}$ & 4 & 189.25 & 33.60 & 55.5 \\
\hline Sample 28 & M & 4 & 60.41 & 108.51 & 370.9 \\
\hline Sample 29 & $\mathrm{~F}$ & 4 & 186.16 & 31.3 & 322.1 \\
\hline Sample 30 & $\mathrm{M}$ & 4 & 115.51 & 31.3 & 770.97 \\
\hline Sample 31 & M & 4 & 202.5 & 66.31 & 461.3 \\
\hline Sample 32 & $\mathrm{~F}$ & 4 & 45.15 & 31.2 & 108.95 \\
\hline Sample 33 & $\mathrm{~F}$ & 4 & 212.71 & 31.3 & 793.23 \\
\hline Sample 34 & $\mathrm{~F}$ & 4 & 104.22 & 65.10 & 258.26 \\
\hline
\end{tabular}

to a comicrobial infection, and/or a patient's infection was in the acute or after acute phase. The latter suggestion may agree with the results of Aceti et al. [41], where a high anamnestic response in defensin concentration was reported after in vitro stimulation of PBMCs from chronic $\mathrm{HCV}$-infected patients with HCV proteins (see below).

These results are generally consistent with the only two studies currently available in literature [41, 42]. One report evaluated $\alpha$ - and $\beta$-defensin concentrations in human peripheral blood by measuring mRNA copy number [42], while the second evaluated $\alpha$-defensin mRNA copy number in human peripheral blood mononuclear cells (PBMCs) of patients with chronic HCV infection, after in vitro induction with HCV C proteins [41]. Fang et al. [42] concluded that human peripheral blood $\beta$-defensins 1 and 2 (DEFB1 and $D E F B 2$ ) genes were transiently expressed following induction 
with lipopolysaccharide or heat-inactivated bacterial cells, whereas $\alpha$-defensins 1-3 (DEFA1-3) genes were constitutively transcribed while the $\beta$-defensin 3 (DEFB3) gene was not expressed. The inducible expression of $D E F B 1$ and $D E F B 2$ genes displayed interindividual variability; however, the study did not indicate serum concentrations of defensin peptides.

Aceti et al. [41], however, identified and quantified $\alpha$-defensins in PBMCs using mass spectrometry, ELISA, antibacterial activity, and mRNA levels. PBMCs from 3 patients and controls were stimulated with $\mathrm{HCV}$ core protein and hepatitis B virus antigen in vitro as well as the $\alpha$ defensin mRNAs level was quantified. The authors found that HCV C protein activates transcription of $\alpha$-defensin in vitro, and $\alpha$-defensin peptide levels were accordingly significantly increased in patients with chronic hepatitis C (1.103 \pm $0.765 \mathrm{ng} / 10^{6}$ cells $)$ and chronic hepatitis $B(0.53 \pm 0.15)$ compared to healthy controls $(0.217 \pm 0.09 ; P<0.001)$. In patients with chronic hepatitis $\mathrm{C}$, levels of $\alpha$-defensin and antibacterial activity correlated with the liver fibrosis. Aceti et al. [41] suggested that HCV induces $\alpha$-defensin expression and that the high linear correlation of $\alpha$-defensin levels with advancing fibrosis makes measuring these peptides a reliable marker of fibrosis stage.

Higher concentrations of both $\alpha$ - and $\beta$-defensins in our samples may indicate an immune response profile in these patients. The Th-1 immunity profile (IL-2, IL-12, TNF- $\alpha$, and IFN- $\gamma$ ) is correlated with liver fibrosis in patients with chronic hepatitis C, whereas Th2 immunity profile (IL-4 and IL-10) cannot control viral clearance [43]. Defensins are considered to be inducers of proinflammatory cytokines (TNF- $\alpha$ and IFN- $\gamma$ ) and the Th1-skewed immune response [30]. Recently, patients with severe liver fibrosis presented lower frequency of circulating CD8+ T-cells, higher levels of proinflammatory cytokines, lower levels of IL-10, and higher levels of proinflammatory cytokines (TNF and IFN- $\gamma$ ) [44], in line with a previous report that found a linear correlation between $\alpha$ defensin levels and advancing liver fibrosis [41].

In a study by Erhart et al. [45], the expressions of various $\alpha$-and $\beta$-defensins in biopsy samples taken from 35 patients infected with genital (warts) papillomavirus were analysed. The authors found significantly higher expression of $\beta$ defensin hBD-1 $(P=0.03)$, hBD-2 $(P<0.01)$, and hBD$3(P<0.001)$, while $\alpha$-defensins (HNPs $1-3)$ were scarcely detectable in normal and viral infected tissues [45].

Generally, humans express $6 \alpha$-defensins and multiple $\beta$ defensin peptides. A-defensins 1-3 are especially abundant in human neutrophils, constituting $30-50 \%$ of the total protein of their azurophil granules [46-48]. Although plasma levels of $\alpha$-defensins normally vary between 40 and $200 \mathrm{ng} / \mathrm{mL}$, higher levels are found at sites of infection, and plasma levels $>100 \mu \mathrm{g} / \mathrm{mL}$ may occur during sepsis, intrauterine infections, and bacterial meningitis [47-55]. These plasma $\alpha$-defensin concentrations are higher than those estimated in our study in normal serum, which may reflect the differences in the methods of measurement used.

Increased plasma and bronchoalveolar lavage levels of $\alpha$ defensins have been reported in individuals with Mycobacterium avium-intracellulare infection and pulmonary tuberculosis $[53,54]$. A-defensin concentrations were not correlated with infection with Mycobacterium tuberculosis and/or its multidrug resistant strain [56]. A-defensins are active against a variety of gram-positive and gram-negative bacteria as well as fungi and parasites $[47,57]$.

Defensins are considered as one of strongest types of central and peripheral defenders, especially in mucosal tissues. They also link the innate and adaptive immunity. There is a close correlation between increased concentrations of $\alpha$ - and $\beta$-defensins in vaginal tissues and fluids following infection. An enormous increase in $\alpha$-defensins and their secretory neutrophils in the vaginal during endometritis was reported [52]. Fan et al. [58] have shown that concentrations of human $\beta$-defensin 2 and $\alpha$-defensin 5 were increased in women with vaginosis, which the authors considered to be an immune response against bacterial invasion [58]. This was later confirmed [59]; the group showed that bacterial vaginosis was associated with lower vaginal concentrations of $\beta$-defensin 3 , but not $\beta$-defensin 2 or $\alpha$-defensins 1-3, in pregnant women. Baricelli et al. [60] added that $\beta$-defensin 2 was secreted in the milk of lactating women. Interestingly, levels of $\beta$-defensin 2 were found to be significantly higher in colostrum than in mature milk samples [60]. The increased concentrations of various types of defensins in clinical conditions compared to normal health are not limited to microbial infections but extend to different kinds of human diseases [31, 61, 62].

Human natural $\alpha$-defensins (HNPs 1, 2, and 3) concentrations should only be compared with the total amount of HNPs $1-3$, measured by radio- and immunoassays. Reportedly, HNPs 1-3 serum concentrations measured with RIA [63] were found to be $250 \mathrm{ng} / \mathrm{mL}$ in controls sera, while they were 500 to $1750 \mathrm{ng} / \mathrm{mL}$ in patients with various lung diseases. In another study, HNPs 1-3 concentrations in serum were measured with ELISA [64] and revealed as $\pm 7 \mathrm{ng} / \mathrm{mL}$ in normal individuals and were significantly increased in colon cancer patients with a median concentration of around 15$29 \mathrm{ng} / \mathrm{mL}$. When comparing the total amount of HNPs 1,2 , and 3 , as measured using the developed assay, in serum from IC patients (an average of $1076 \mathrm{ng} / \mathrm{mL}$ ), these levels complied with the increased concentrations found in the study by Mukae et al. [63], whereas the total measured amounts in the serum batches used for the selectivity assessment (an average of $309 \mathrm{ng} / \mathrm{mL}$ ) were comparable with the concentrations in healthy controls in the same study [61]. More studies have reported HNPs 1-3 concentrations in plasma: around 200$400 \mathrm{ng} / \mathrm{mL}$ in healthy controls, when measured with RIA $[31,53-55,63,65,66]$, and around $40-100 \mathrm{ng} / \mathrm{mL}$ when measured with ELISA [51, 67, 68]. Recent measurements in different plasma batches, used for selectivity assessment, showed between 40 and $175 \mathrm{ng} / \mathrm{mL}$ and seem comparable with the concentrations measured using the ELISA method [69].

Since 1997, the worldwide pioneer in the defensins, Lehrer [70], raised fundamental questions regarding defensins concentrations in disease and other related issues. Although a $50 \mathrm{~kg}$ female or $70 \mathrm{~kg}$ male will produce at least 250 $700 \mathrm{mg}$ defensins daily (more when neutrophilic leukocytosis occurs), the low levels of defensins in normal plasma $(254.8 \mathrm{pg} / \mathrm{mL})$ account for $0.05 \%$ of baseline daily production. Where are the rest of these peptides? Are defensins rapidly degraded, and if so, where does this process occur? Do 
extracellular defensins leave the circulation as rapidly as they enter it (an easy question, from the standpoint of steady-state kinetics), and how rapidly do they enter it (a more challenging question)? How short is the half-life of plasma defensins and do they recirculate or traverse epithelial barriers? Do extracellular defensins permeate tissues such as the lungs and the gastrointestinal tract? Do they impregnate epithelial cells, basement membranes, and mucosal tissues? All of these crucial questions are yet to be comprehensively and satisfactorily answered.

Although there is a clear correlation between the results presented here and previous reports of human circulated defensin concentrations, the exact concentrations of defensins in health and disease remain to be determined.

To conclude, circulated defensins are measured at significantly higher concentration in $\mathrm{HCV}$-infected patients compared to healthy individuals. Total, $\alpha$-, and $\beta$-defensin concentrations are all elevated by tenfold in patients with $\mathrm{HCV}$ infections.

\section{Disclosure}

The current work is a part of the Ph.D. thesis of Mr. Ehab Hussein Mattar (Department of Biology, Faculty of Science, King Abdulaziz University).

\section{Competing Interests}

The authors declare that there are no competing interests.

\section{Acknowledgments}

The authors thank Professors Drs. Khaleid Aljhmdi and Usama Abuzenadh for their continued support.

\section{References}

[1] A. Varaklioti, N. Vassilaki, U. Georgopoulou, and P. Mavromara, "Alternate translation occurs within the core coding region of the hepatitis C viral genome," The Journal of Biological Chemistry, vol. 277, no. 20, pp. 17713-17721, 2002.

[2] C. M. Rice, "Flaviviridae: the viruses and their replication," in Fields Virology, B. N. Fields, D. M. Knipe, and P. M. Howley, Eds., pp. 931-956, Lippincott-Raven, Philadelphia, Pa, USA, 3rd edition, 1996.

[3] N. Kato, M. Hijikata, Y. Ootsuyama et al., "Molecular cloning of the human hepatitis $C$ virus genome from Japanese patients with non-A, non-B hepatitis," Proceedings of the National Academy of Sciences of the United States of America, vol. 87, no. 24, pp. 9524-9528, 1990.

[4] J. Nakabayashi, "A compartmentalization model of hepatitis C virus replication: an appropriate distribution of HCV RNA for the effective replication," Journal of Theoretical Biology, vol. 300, pp. 110-117, 2012.

[5] D. A. Saleh, F. Shebl, M. Abdel-Hamid et al., "Incidence and risk factors for hepatitis C infection in a cohort of women in rural Egypt," Transactions of the Royal Society of Tropical Medicine and Hygiene, vol. 102, no. 9, pp. 921-928, 2008.

[6] T. Poynard, P. Marcellin, S. S. Lee et al., "Randomised trial of interferon $\alpha 2 \mathrm{~b}$ plus ribavirin for 48 weeks or for 24 weeks versus interferon $\alpha 2 \mathrm{~b}$ plus placebo for 48 weeks for treatment of chronic infection with hepatitis C virus," The Lancet, vol. 352, no. 9138, pp. 1426-1432, 1998.

[7] T. Okanoue, Y. Itoh, M. Minami et al., "Interferon therapy lowers the rate of progression to hepatocellular carcinoma in chronic hepatitis $\mathrm{C}$ but not significantly in an advanced stage: a retrospective study in 1148 patients," Journal of Hepatology, vol. 30, no. 4, pp. 653-659, 1999.

[8] FDA, http://hepatitiscnewdrugresearch.com/approved-treatmentsfor-hepatitis-c.html.

[9] X. Qian, Y.-Z. Zhu, P. Zhao, and Z.-T. Qi, "Entry inhibitors: new advances in HCV treatment," Emerging Microbes \& Infections, vol. 5, article e3, 2016.

[10] A. Izadpanah and R. L. Gallo, "Antimicrobial peptides," Journal of the American Academy of Dermatology, vol. 52, no. 3, pp. 381392, 2005.

[11] C. Beisswenger and R. Bals, "Functions of antimicrobial peptides in host defense and immunity," Current Protein and Peptide Science, vol. 6, no. 3, pp. 255-264, 2005.

[12] K. A. Brogden, "Antimicrobial peptides: pore formers or metabolic inhibitors in bacteria?" Nature Reviews Microbiology, vol. 3, no. 3, pp. 238-250, 2005.

[13] Y. J. Gordon, E. G. Romanowski, and A. M. McDermott, "A review of antimicrobial peptides and their therapeutic potential as anti-infective drugs," Current Eye Research, vol. 30, no. 7, pp. 505-515, 2005.

[14] Y. Nie, X.-C. Zeng, Y. Yang et al., "A novel class of antimicrobial peptides from the scorpion Heterometrus spinifer," Peptides, vol. 38, no. 2, pp. 389-394, 2012.

[15] O. Toke, "Antimicrobial peptides: new candidates in the fight against bacterial infections," Biopolymers-Peptide Science Section, vol. 80, no. 6, pp. 717-735, 2005.

[16] M. E. Selsted and A. J. Ouellette, "Mammalian defensins in the antimicrobial immune response," Nature Immunology, vol. 6, no. 6, pp. 551-557, 2005.

[17] M. Pazgier, D. M. Hoover, D. Yang, W. Lu, and J. Lubkowski, "Human $\beta$-defensins," Cellular and Molecular Life Sciences, vol. 63, no. 11, pp. 1294-1313, 2006.

[18] T. Ganz, M. E. Selsted, D. Szklarek et al., "Defensins. Natural peptide antibiotics of human neutrophils," The Journal of Clinical Investigation, vol. 76, no. 4, pp. 1427-1435, 1985.

[19] B. Ericksen, Z. Wu, W. Lu, and R. I. Lehrer, "Antibacterial activity and specificity of the six human $\alpha$-defensins," Antimicrobial Agents and Chemotherapy, vol. 49, no. 1, pp. 269-275, 2005.

[20] R. C. Rodríguez de la Vega and L. D. Possani, "On the evolution of invertebrate defensins," Trends in Genetics, vol. 21, no. 6, pp. 330-332, 2005.

[21] J. A. Hoffmann and C. Hetru, "Insect defensins: inducible antibacterial peptides," Immunology Today, vol. 13, no. 10, pp. 411415, 1992.

[22] F. T. Lay and M. A. Anderson, "Defensins-components of the innate immune system in plants," Current Protein and Peptide Science, vol. 6, no. 1, pp. 85-101, 2005.

[23] T. Ganz, "Defensins: antimicrobial peptides of innate immunity," Nature Reviews Immunology, vol. 3, no. 9, pp. 710-720, 2003.

[24] T. Ganz, "Defensins: antimicrobial peptides of vertebrates," Comptes Rendus Biologies, vol. 327, no. 6, pp. 539-549, 2004.

[25] T. Ganz, "Defensins and other antimicrobial peptides: a historical perspective and an update," Combinatorial Chemistry and High Throughput Screening, vol. 8, no. 3, pp. 209-217, 2005. 
[26] N. A. El-Baky, V. N. Uversky, and E. M. Redwan, "Human consensus interferons: bridging the natural and artificial cytokines with intrinsic disorder," Cytokine and Growth Factor Reviews, vol. 26, no. 6, pp. 637-645, 2015.

[27] D. Yang, A. Biragyn, L. W. Kwak, and J. J. Oppenheim, "Mammalian defensins in immunity: more than just microbicidal," Trends in Immunology, vol. 23, no. 6, pp. 291-296, 2002.

[28] C. Kim and S. H. E. Kaufmann, "Defensin: a multifunctional molecule lives up to its versatile name," Trends in Microbiology, vol. 14, no. 10, pp. 428-431, 2006.

[29] J. Shi, "Defensins and Paneth cells in inflammatory bowel disease," Inflammatory Bowel Diseases, vol. 13, no. 10, pp. 12841292, 2007.

[30] E. H. Mattar, H. A. Almehdar, H. A. Yacoub, V. N. Uversky, and E. M. Redwan, "Antimicrobial potentials and structural disorder of human and animal defensins," Cytokine \& Growth Factor Reviews, vol. 28, pp. 95-111, 2016.

[31] T. Ihi, M. Nakazato, H. Mukae, and S. Matsukura, "Elevated concentrations of human neutrophil peptides in plasma, blood, and body fluids from patients with infections," Clinical Infectious Diseases, vol. 25, no. 5, pp. 1134-1140, 1997.

[32] J. D. Scott and D. R. Gretch, "Molecular diagnostics of hepatitis C virus infection: a systematic review," The Journal of the American Medical Association, vol. 297, no. 7, pp. 724-732, 2007.

[33] E.-R. M. Redwan and M. K. AL-Awady, "Prevalence of tetanus immunity in the Egyptian population," Human Antibodies, vol. 11, no. 1-2, pp. 55-59, 2002.

[34] E.-R. M. Redwan, "Biochemical and immunological properties of four intravenous immunoglobulin G preparations," Human Antibodies, vol. 11, no. 3, pp. 79-84, 2002.

[35] E. M. Redwan and M. K. El-Awady, "Status of diphtheria immunity in the Egyptian population," Annals of Tropical Medicine and Parasitology, vol. 99, no. 1, pp. 93-99, 2005.

[36] E.-R. M. Redwan, A. Khalil, and Z. Z. EL-Dardiri, "Production and purification of ovine anti-tetanus antibody," Comparative Immunology, Microbiology and Infectious Diseases, vol. 28, no. 3, pp. 167-176, 2005.

[37] E. B. Mallow, A. Harris, N. Salzman et al., "Human enteric defensins. Gene structure and developmental expression," The Journal of Biological Chemistry, vol. 271, no. 8, pp. 4038-4045, 1996.

[38] A. Ouellette and J. C. Lualdi, "A novel mouse gene family coding for cationic, cysteine-rich peptides. Regulation in small intestine and cells of myeloid origin," The Journal of Biological Chemistry, vol. 265, no. 17, pp. 9831-9837, 1990.

[39] M. E. Selsted, Y.-Q. Tang, W. L. Morris et al., "Purification, primary structures, and antibacterial activities of beta-defensins, a new family of antimicrobial peptides from bovine neutrophils," The Journal of Biological Chemistry, vol. 268, no. 9, pp. 6641$6648,1993$.

[40] Y.-Q. Tang, J. Yuan, G. Ösapay et al., "A cyclic antimicrobial peptide produced in primate leukocytes by the ligation of two truncated $\alpha$-defensins," Science, vol. 286, no. 5439, pp. 498-502, 1999.

[41] A. Aceti, M. L. Mangoni, C. Pasquazzi et al., “ $\alpha$-Defensin increase in peripheral blood mononuclear cells from patients with hepatitis C virus chronic infection," Journal of Viral Hepatitis, vol. 13, no. 12, pp. 821-827, 2006.

[42] X.-M. Fang, Q. Shu, Q.-X. Chen et al., "Differential expression of $\alpha$ - and $\beta$-defensins in human peripheral blood," European Journal of Clinical Investigation, vol. 33, no. 1, pp. 82-87, 2003.
[43] E. Gigi, M. Raptopoulou-Gigi, A. Kalogeridis et al., "Cytokine mRNA expression in hepatitis $\mathrm{C}$ virus infection: TH-1 predominance in patients with chronic hepatitis C and TH1-TH2 cytokine profile in subjects with self-limited disease," Journal of Viral Hepatitis, vol. 15, no. 2, pp. 145-154, 2008.

[44] S. de Souza-Cruz, M. B. Victória, A. M. Tarragô et al., "Liver and blood cytokine microenvironment in $\mathrm{HCV}$ patients is associated to liver fibrosis score: a proinflammatory cytokine ensemble orchestrated by TNF and tuned by IL-10," BMC Microbiology, vol. 16, no. 1, article 3, 2016.

[45] W. Erhart, Ö. Alkasi, G. Brunke et al., "Induction of human $\beta$ defensins and psoriasin in vulvovaginal human papillomavirusassociated lesions," Journal of Infectious Diseases, vol. 204, no. 3, pp. 391-399, 2011.

[46] M. Salvatore, A. Garcia-Sastre, P. Ruchala, R. I. Lehrer, T. Chang, and M. E. Klotman, "alpha-defensin inhibits influenza virus replication by cell-mediated mechanism(s," The Journal of Infectious Diseases, vol. 196, no. 6, pp. 835-843, 2007.

[47] M. E. Klotman and T. L. Chang, "Defensins in innate antiviral immunity," Nature Reviews Immunology, vol. 6, no. 6, pp. 447456, 2006.

[48] R. I. Lehrer, "Primate defensins," Nature Reviews Microbiology, vol. 2, no. 9, pp. 727-738, 2004.

[49] T. Ganz and R. I. Lehrer, "Defensins," Pharmacology and Therapeutics, vol. 66, no. 2, pp. 191-205, 1995.

[50] F. A. Maffei, R. P. Heine, M. J. Whalen, L. F. Mortimer, and J. A. Carcillo, "Levels of antimicrobial molecules defensin and lactoferrin are elevated in the cerebrospinal fluid of children with meningitis," Pediatrics, vol. 103, no. 5, pp. 987-992, 1999.

[51] A. V. Panyutich, E. A. Panyutich, V. A. Krapivin, E. A. Baturevich, and T. Ganz, "Plasma defensin concentrations are elevated in patients with septicemia or bacterial meningitis," The Journal of Laboratory and Clinical Medicine, vol. 122, no. 2, pp. 202-207, 1993.

[52] H. C. Wiesenfeld, R. P. Heine, M. A. Krohn et al., "Association between elevated neutrophil defensin levels and endometritis," Journal of Infectious Diseases, vol. 186, no. 6, pp. 792-797, 2002.

[53] J.-I. Ashitani, H. Mukae, Y. Arimura, A. Sano, M. Tokojima, and M. Nakazato, "High concentrations of $\alpha$-defensins in plasma and bronchoalveolar lavage fluid of patients with acute respiratory distress syndrome," Life Sciences, vol. 75, no. 9, pp. 1123-1134, 2004.

[54] J.-I. Ashitani, H. Mukae, T. Hiratsuka, M. Nakazato, K. Kumamoto, and S. Matsukura, "Plasma and BAL fluid concentrations of antimicrobial peptides in patients with Mycobacterium avium-intracellulare infection," Chest, vol. 119, no. 4, pp. 1131-1137, 2001.

[55] J.-I. Ashitani, H. Mukae, T. Hiratsuka, M. Nakazato, K. Kumamoto, and S. Matsukura, "Elevated levels of $\alpha$-defensins in plasma and BAL fluid of patients with active pulmonary tuberculosis," Chest, vol. 121, no. 2, pp. 519-526, 2002.

[56] L.-M. Zhu, C.-H. Liu, P. Chen et al., "Multidrug-resistant tuberculosis is associated with low plasma concentrations of human neutrophil peptides 1-3," International Journal of Tuberculosis and Lung Disease, vol. 15, no. 3, pp. 369-374, 2011.

[57] H.-Y. Lee, A. Andalibi, P. Webster et al., "Antimicrobial activity of innate immune molecules against Streptococcus pneumoniae, Moraxella catarrhalis and nontypeable Haemophilus influenzae," BMC Infectious Diseases, vol. 4, article 12, 2004.

[58] S. R. Fan, X. P. Liu, and Q. P. Liao, "Human defensins and cytokines in vaginal lavage fluid of women with bacterial 
vaginosis," International Journal of Gynecology and Obstetrics, vol. 103, no. 1, pp. 50-54, 2008.

[59] C. Mitchell, M. L. Gottsch, C. Liu, D. N. Fredricks, and D. B. Nelson, "Associations between vaginal bacteria and levels of vaginal defensins in pregnant women," American Journal of Obstetrics and Gynecology, vol. 208, no. 2, pp. 132-e7, 2013.

[60] J. Baricelli, M. A. Rocafull, D. Vázquez, B. Bastidas, E. BáezRamirez, and L. E. Thomas, " $\beta$-defensin- 2 in breast milk displays a broad antimicrobial activity against pathogenic bacteria," Jornal de Pediatria, vol. 91, no. 1, pp. 36-43, 2015.

[61] Y. Arimura, J.-I. Ashitani, S. Yanagi et al., "Elevated serum $\beta$ defensins concentrations in patients with lung cancer," Anticancer Research, vol. 24, no. 6, pp. 4051-4057, 2004.

[62] A. Weinberg, G. Jin, S. Sieg, and T. S. McCormick, "The Yin and Yang of human beta-defensins in health and disease," Frontiers in Immunology, vol. 3, article 294, 2012.

[63] H. Mukae, H. Iiboshi, M. Nakazato et al., "Raised plasma concentrations of $\alpha$-defensins in patients with idiopathic pulmonary fibrosis," Thorax, vol. 57, no. 7, pp. 623-628, 2002.

[64] C. Melle, G. Ernst, B. Schimmel et al., "Discovery and identification of $\alpha$-defensins as low abundant, tumor-derived serum markers in colorectal cancer," Gastroenterology, vol. 129, no. 1, pp. 66-73, 2005.

[65] K. Shiomi, M. Nakazato, T. Ihi, K. Kangawa, H. Matsuo, and S. Matsukura, "Establishment of radioimmunoassay for human neutrophil peptides and their increases in plasma and neutrophil in infection," Biochemical and Biophysical Research Communications, vol. 195, no. 3, pp. 1336-1344, 1993.

[66] N. Yamaguchi, H. Isomoto, H. Mukae et al., "Concentrations of $\alpha$ - and $\beta$-defensins in plasma of patients with inflammatory bowel disease," Inflammation Research, vol. 58, no. 4, pp. 192197, 2009.

[67] J. Albrethsen, C. H. Møller, J. Olsen, H. Raskov, and S. Gammeltoft, "Human neutrophil peptides 1, 2 and 3 are biochemical markers for metastatic colorectal cancer," European Journal of Cancer, vol. 42, no. 17, pp. 3057-3064, 2006.

[68] S. Kanmura, H. Uto, M. Numata et al., "Human neutrophil peptides 1-3 are useful biomarkers in patients with active ulcerative colitis," Inflammatory Bowel Diseases, vol. 15, no. 6, pp. 909-917, 2009.

[69] I. van den Broek, R. W. Sparidans, J. H. M. Schellens, and J. H. Beijnen, "Validation of a quantitative assay for human neutrophil peptide-1, -2 , and -3 in human plasma and serum by liquid chromatography coupled to tandem mass spectrometry," Journal of Chromatography B: Analytical Technologies in the Biomedical and Life Sciences, vol. 878, no. 15-16, pp. 1085-1092, 2010.

[70] R. I. Lehrer, "Editorial response: questions and answers about defensins," Clinical Infectious Diseases, vol. 15, pp. 1141-1142, 1997. 


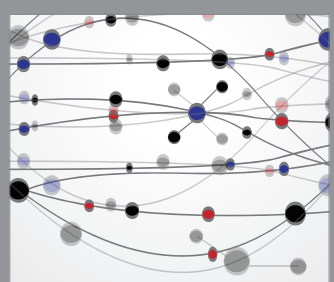

The Scientific World Journal
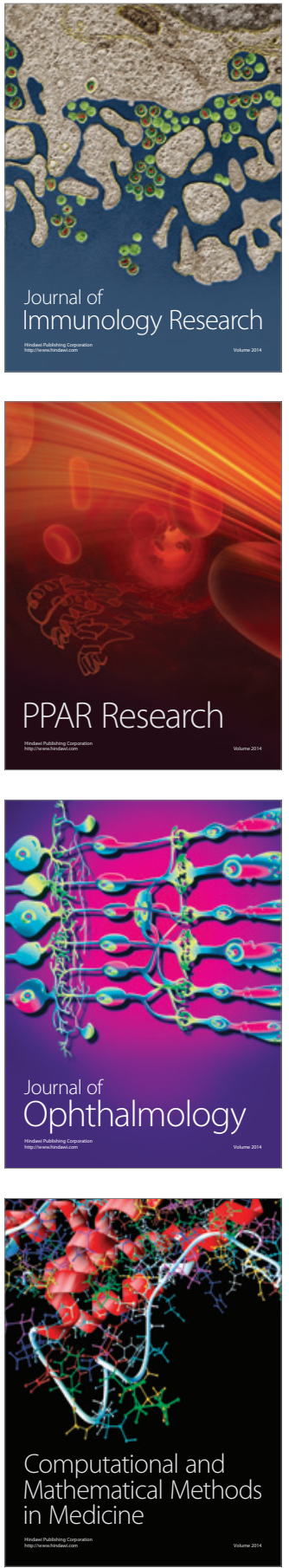

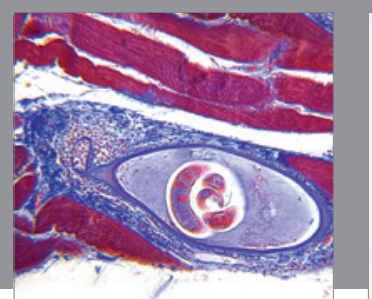

Gastroenterology Research and Practice

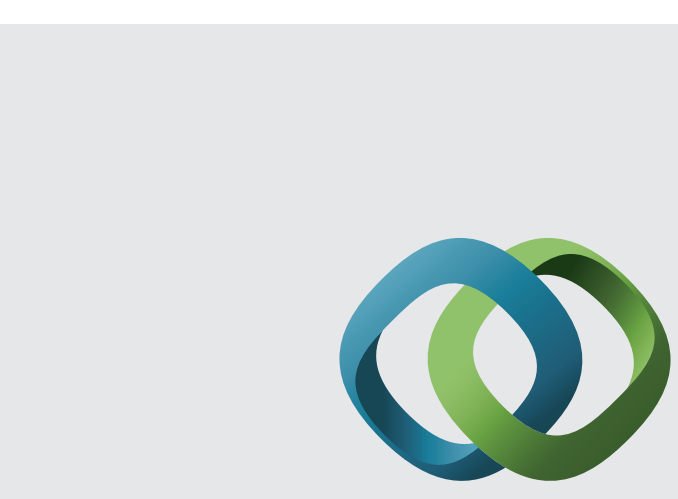

\section{Hindawi}

Submit your manuscripts at

http://www.hindawi.com
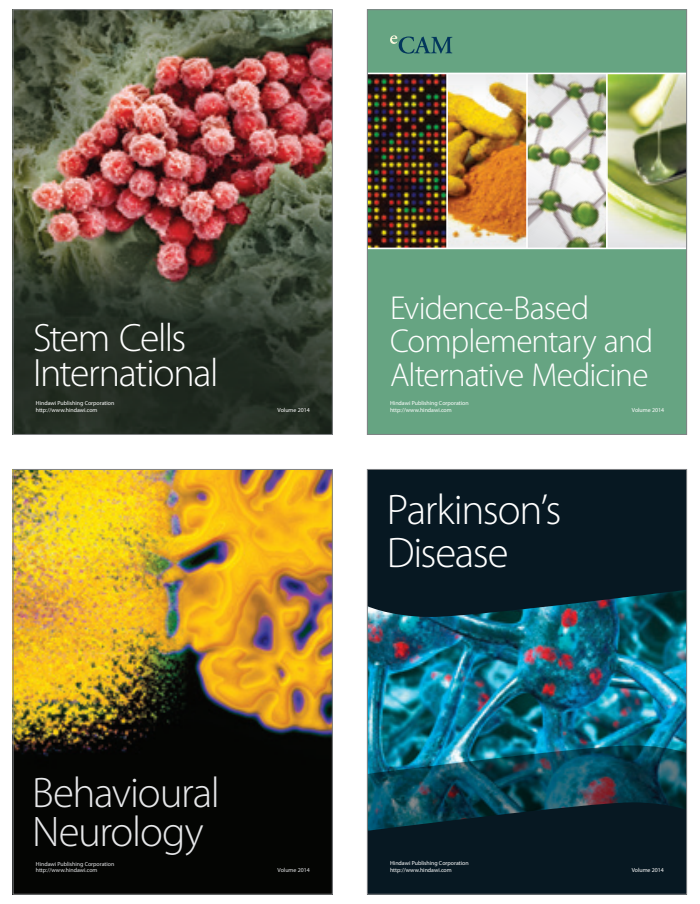
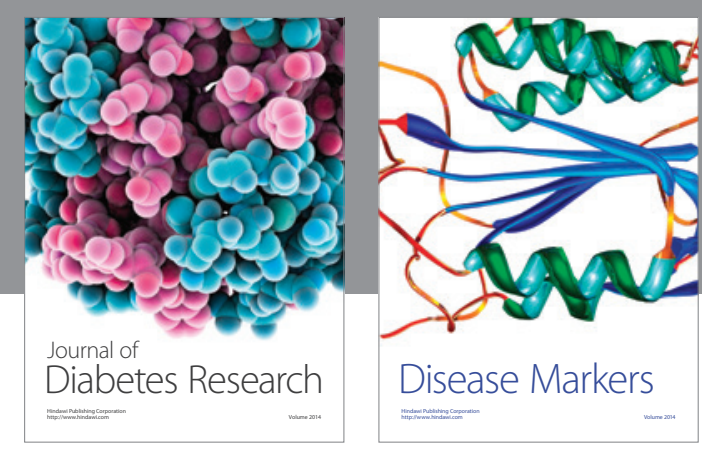

Disease Markers
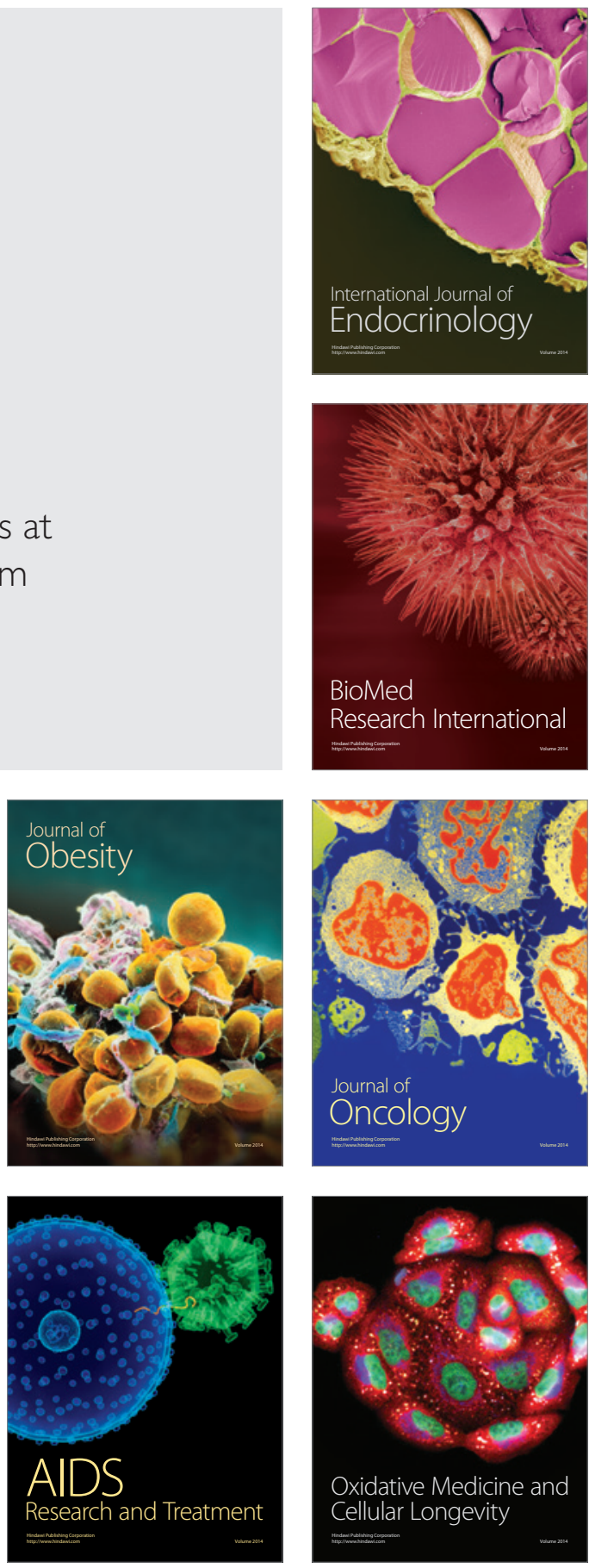